\title{
SOLID FREEBODY FORMING OF CERAMICS FROM POLYMERIZABLE SLURRY
}

Kevin Stuffle, Anthony Mulligan, Paul Calvert* and John Lombardi* ACR, Tucson, Arizona; *Arizona Materials Laboratories, Tucson Arizona.

\section{INTRODUCTION}

In solid free body forming a component is described by a CAD system as a series of slices. The slices are deposited as a sequence of layers which are cured or solidified by a moving head such that a three dimensional part is built up. Systems have been developed based on photocurable polymers, solidifying polymer melts, laser fused powder layers, polymer-bound powders and others.

Difficulties with such systems to date include the low strength of many of the polymer systems and poor resolution. The polymeric components can be used as forms to make molds for later casting of metals or ceramics. The powder components can be sintered to higher density.

In the system described here, the part is built up by deposition of a slurry of ceramic powder in liquid acrylic monomer. As each layer is deposited the monomer is heat-cured. When the whole component is formed, the polymer is burnt-out and the ceramic is sintered.

\section{DELIVERY SYSTEM}

The slurry was contained in a $50 \mathrm{ml}$ polypropylene syringe which was connected to an argon pressure line to drive the liquid through a needle of $0.3-1.3 \mathrm{~mm}$ diameter. The delivery was started and stopped by a shut-off valve with pressure venting in the air line.

\section{SLURRY}

Slurries of Alumina $\left(\mathrm{Al}_{2} \mathrm{O}_{3}-0.5 \mathrm{wt} \% \mathrm{MgO}\right.$, Ceralox Corp.) in liquid acrylic monomers were prepared. The formulations, based on the work of Janney [1], are shown in Table 1. Similar monomer systems have been used for tape casting of ceramic sheets by various workers [2]. Alumina solids loadings up to 53 vol\% were used. The acrylate monomers have the advantage of curing very rapidly. Since they are polyfunctional, high degrees of polymerization are not necessary to achieve high molecular weight or gelation. The polymerization rate and brittleness of the resin was controlled by addition of dibasic esters, a mixture of primarily dimethyl glutarate and succinate. Viscosity increases with solids loading as shown in Figure 1. Figure 2 shows 
slurry flow rates as a function of applied pressure through a $0.33 \mathrm{~mm}$ needle, $1.27 \mathrm{~cm}$ long.

Table 1: Composition of Acrylic Monomer Formulations

\begin{tabular}{||l|l|l|l|l|l|l|l||}
\hline Alumina, wt\% & 26.2 & 34.0 & 39.5 & 42.5 & 45.1 & 47.7 & 48.9 \\
\hline Triton X-100, wt\% & 7.8 & 10.1 & 10.3 & 9.8 & 9.3 & 10.8 & 10.5 \\
\hline TMPTA, wt\% & 3.4 & 4.4 & 4.0 & 3.8 & 3.6 & 3.6 & 3.2 \\
\hline HODA, wt\% & 29.6 & 38.3 & 34.5 & 32.8 & 31.3 & 28.2 & 27.9 \\
\hline DBE, wt\% & 32.9 & 13.1 & 39.5 & 11.2 & 10.7 & 9.7 & 9.5 \\
\hline Mill time, hr & 24 & 24 & 21 & 21 & 41 & 49 & 49 \\
\hline Density, g/ml & 1.54 & 1.75 & 2.01 & 2.00 & 2.16 & 2.19 & 2.23 \\
\hline Viscosity, P & 6 & 12 & 29 & 50 & 112 & 127 & 146 \\
\hline
\end{tabular}

HODA: Hexanedioldiacrylate, TMPTA: Trimethylolpropanetriacrylate, DBE: Dibasic ester, plasticizer.

\section{DEPOSITION AND CURING}

Thin layers of slurry were deposited onto a heated platen at about $120^{\circ} \mathrm{C}$. The temperature was adjusted to give rapid curing and good shape definition. Oxygen inhibition of the polymerization leaves the surface tacky and improves the degree of bonding between successive layers.

\section{FIBER REINFORCEMENT}

Carbon fibers $1 \mu \mathrm{m}$ in diameter were milled for 30 hours with the slurry, to produce fibers with a length of about $200 \mu \mathrm{m}$. With $1 \%$ fiber content these slurries flowed readily through the needle and were formed into parts. Fibers tended to align horizontally in each layer. The resulting green parts appeared to be tougher and easier to handle than unreinforced parts. 
Figure 1: Viscosity vs volume \% ceramic loading

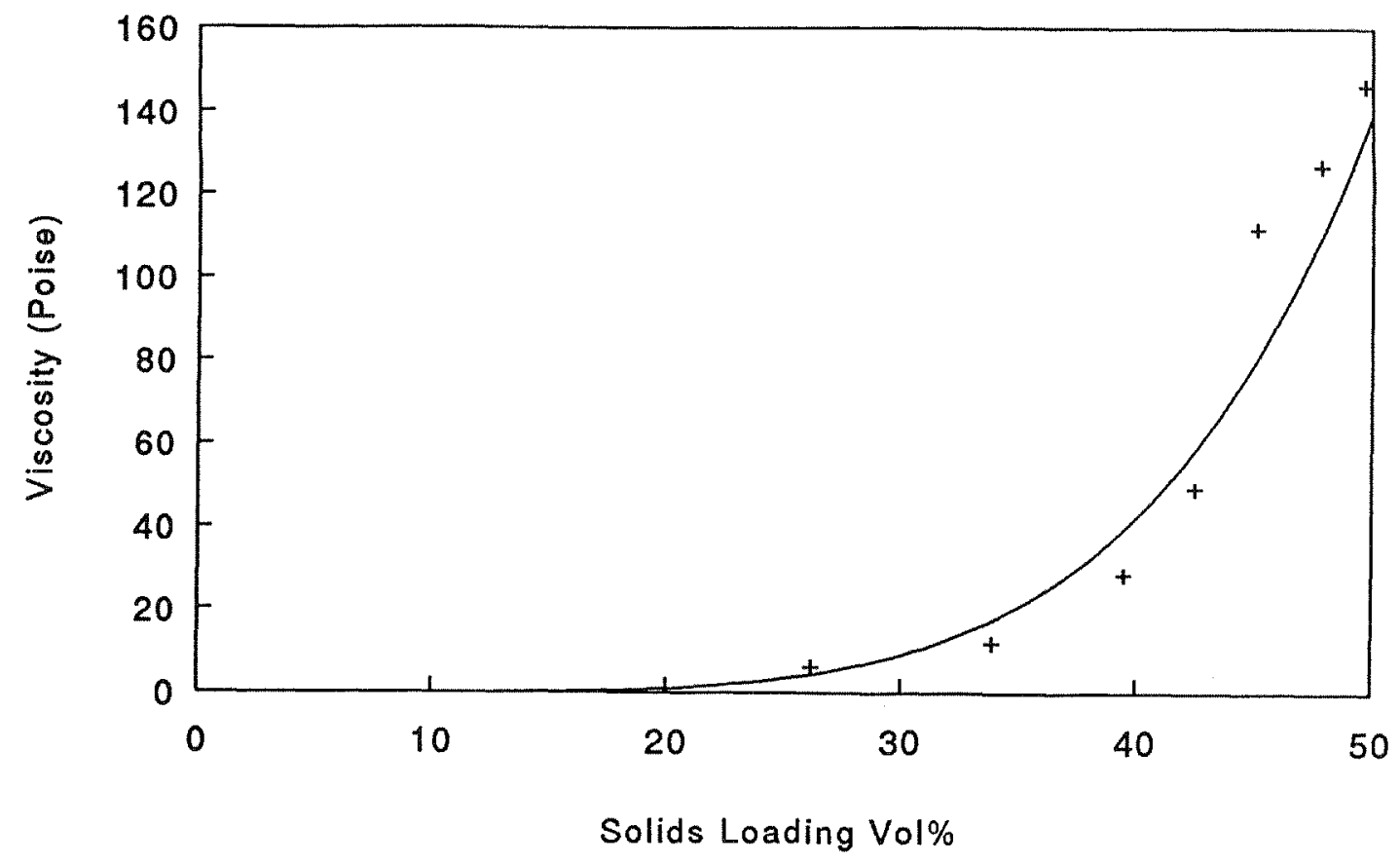

Figure 2: Flow rate vs. pressure profiles for alumina slurries

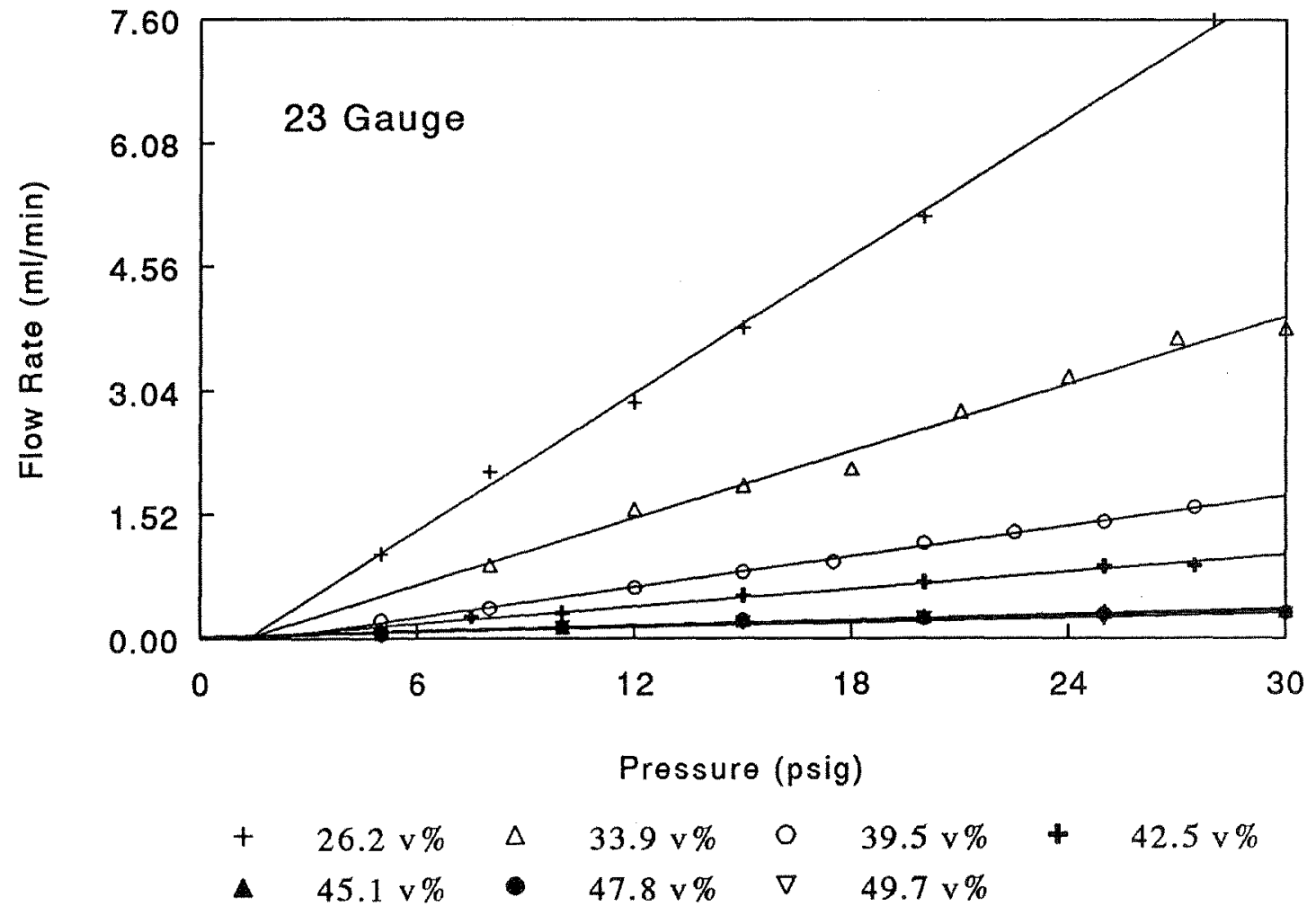




\section{PART PRODUCTION}

Flat plates and thin walled cylinders were produced in monolithic alumina using simple machine instructions to a head mounted on an X-Y table. A nozzle of $0.33 \mathrm{~mm}$ was used with a slurry pump pressure of 22 psig and a nozzle linear speed of 100 $\mathrm{cm} / \mathrm{min}$.

\section{PART PROPERTIES}

Green parts had a density of about $60 \%$ of theoretical, based on pure alumina. After firing densities range from 3.64 to 3.94 (90-99\% of theoretical). Flexural modulus was measured to be $358 \mathrm{GPa}$ and strengths ranged from 431-606 $\mathrm{MPa}$ for 12 samples in three point bend for a sample $2 " x 1.5 " x 0.2 "$. This compares favorably with commercial alumina.

\section{REFERENCES}

1. M.A.Janney, "Method for molding ceramic powders" U.S. Patent 4,894,194; Jan 161990.

2. R.R.Landham, P.Nahass, D.K.Leung, M.Ungereit, W.E.Rhine, H.K.Bowen and P.D.Calvert, "Potential use of polymerizable solvents for tape casting ceramics", Amer. Ceram.Soc. Bull. (1987) $\underline{66}, 1513$. 